\title{
ESTADO DA CONSERVAÇÃO AMBIENTAL DAS PASTAGENS DA MUNICIPALIDADE DE ARAPUTANGA-MT, BRASIL
}

\author{
STATE OF ENVIRONMENTAL CONSERVATION THE PASTURES OF THE ARAPUTANGA-MT \\ MUNICIPALITY, BRAZIL
}

(D) Alexander Webber Perlandim Ramos ${ }^{\mathbf{A}}$
(iD) Edinéia Aparecida dos Santos Galvanin ${ }^{\mathbf{B}}$
(iD) Fernanda Vieira Xavier ${ }^{\mathbf{C}}$
(D) Viviane Ferreira Batista ${ }^{\mathbf{A}}$
(iD) Bárbara Regina Batista Soares ${ }^{\mathbf{A}}$
(iD) Úrsula Ruchkys de Azevedo ${ }^{\mathbf{A}}$

${ }^{\text {A }}$ Universidade Federal de Minas Gerais (UFMG), Belo Horizonte, MG, Brasil

${ }^{\text {B } U n i v e r s i d a d e ~ E s t a d u a l ~ P a u l i s t a ~(U N E S P), ~ S a ̃ o ~ P a u l o, ~ S P, ~ B r a s i l ~}$

${ }^{\mathrm{C}}$ Instituto Nacional de Pesquisas do Pantanal (INPP), Cuiabá, MT, Brasil

Recebido em: 12/05/2021 | 11/09/2021ＯOI: 10.12957/tamoios.2021.59793
Correspondência para: Alexander Webber Perlandim Ramos (webber.unemat@gmail.com)

\begin{abstract}
Resumo
O Estado do Mato Grosso se destaca no cenário brasileiro pela elevada produção pecuária, muitas vezes acompanhado de processos que levam a degradação ambiental. Para minimizar os danos relacionados a esses processos, o mapeamento e a caracterização da degradação de pastagens é fundamental. Nesse contexto, o artigo tem como objetivo caracterizar os níveis de degradação das áreas de pastagem do município de Araputanga-MT. Os métodos envolveram a aplicação do Índice de Degradação de Pastagem (IDP) que considera a interrelação entre a cobertura vegetal da pastagem e seu nível de biomassa, permitindo classificar as pastagens em quatro classes: fortemente degradada; moderadamente degradada, levemente degradada e não degradada. Os resultados indicam que 36,24\% das pastagens de Araputanga estão fortemente degradadas; 22,36\% moderadamente; $21,18 \%$ levemente. Apenas 20,22\% das pastagens não apresentam nenhum nível de degradação. Na municipalidade a degradação das pastagens é influenciada pela associação de solos de alta erodibilidade natural (Luvissolos e Neossolos Quartzarênicos) com relevos planos/ondulados marcados por erosões laminares. Para as áreas classificadas como fortemente e moderadamente degradadas é fundamental o estabelecimento ou ampliação de práticas conservacionistas para sua restauração. Essas medidas podem garantir o restabelecimento da produtividade sem a necessidade de desmatamento para abertura de novas áreas de pastagem.
\end{abstract}

Palavras-chave: sensoriamento remoto; erosão; solos; pecuária.

\begin{abstract}
The State of Mato Grosso stands out in the Brazilian scenario for its high livestock production, often accompanied by processes that lead to environmental degradation. To minimize the damage related to these processes, mapping and characterization of pasture degradation is essential. In this context, the article aims to characterize the levels of degradation of the pasture areas of the municipality of Araputanga-MT. The methods involved the application of the Pasture Degradation Index (IDP) that considers the interrelationship between the vegetation cover of the pasture and its biomass level, allowing the ranking of pastures into four classes: strongly degraded; moderately degraded, slightly degraded and not degraded. he results indicate that $36.24 \%$ of araputanga pastures are strongly degraded; $22.36 \%$ moderately; $21.18 \%$ slightly. Only $20.22 \%$ of the pastures do not present any level of degradation. In the municipality the degradation of pastures is influenced by the association of soils of high natural erodibility (Luvisols and Quartzarenic Neosols) with flat/wavy reliefs marked by laminar erosions. For areas classified as strongly and moderately degraded, it is essential to establish or expand conservation practices for their restoration. These measures can ensure the restoration of productivity without the need for deforestation to open up new grazing areas.
\end{abstract}

Keywords: remote sensing; erosion; soils; livestock. 


\section{INTRODUÇÃO}

A erosão tem sido reconhecida como um problema global de degradação ambiental e uma ameaça ao bem-estar social. O uso do solo, desconsiderando suas capacidades de renovação e fragilidades, tem resultado em perdas de áreas com alto potencial econômico, causando muitas vezes transtornos irreversíveis, tais como: processos de arenização e de desertificação, perda da disponibilidade hídrica e empobrecimento de populações.

No cenário brasileiro, a degradação ambiental provocada pelos processos erosivos tem estado em evidência, sobretudo em Mato Grosso, onde o avanço da fronteira agrícola e a atividade pecuária extensiva são acentuados, o que reforça a necessidade da mitigação destes, auxiliando na gestão e no planejamento dos recursos naturais. Somado as más práticas de manejo do solo, as características do relevo mato-grossense favorecem o desencadeamento dos processos erosivos, como destacado por Ribeiro e Salomão (2003); Miranda (2005); Xavier et al. (2010); Faria et al. (2013); Freitas et al. (2017); Carvalho et al. (2017) dentre outros.

No caso do Estado do Mato Grosso os processos erosivos são de natureza morfogenética, ou seja, ainda que os planaltos centrais possuam gêneses estruturais diversas, assumem o caráter residual em função do seu histórico evolutivo. Esses processos estão relacionados às formações geológicas antigas e aos desgastes erosivos que ocorreram em condições paleoclimáticas em que predominaram os processos erosivos sobre os de deposição (sedimentação e acumulação), favorecidos pelo clima quente e úmido. Entre as consequências, estão a formação de solos predominantemente muito intemperizados com alta suscetibilidade a erosão (ROSS, 2006).

A degradação de pastagens é um dos principais causadores dos processos erosivos (UNEP, 2004), sendo um fenômeno global. Estima-se que, cerca de $20 \%$ das pastagens mundiais (naturais e plantadas) estejam degradadas ou em fase de degradação. A degradação de pastagens é um processo dinâmico de degeneração que compromete o ganho de biomassa e, consequentemente, seu desenvolvimento, resultando em uma menor produtividade animal (GALDINHO et al., 2014). Um dos principais gatilhos para a degradação das pastagens está na dificuldade em conceder o tempo necessário aos solos para sua recuperação natural, 
evitando assim o esgotamento de sua capacidade de suporte para que não ocorra sobrepastagem (DIAS-FILHO, 2014).

Nesse sentido, a identificação de pastagens degradadas e sua recuperação podem contribuir para aumentar o Produto Interno Bruto (PIB) do Estado e do país, agregando um viés ecológico para a atividade pecuária, uma vez que a recuperação de pastagens torna desnecessário o desmatamento para abertura de novas áreas, auxiliando assim na preservação de florestas. O mapeamento de focos de degradação de pastagens bem como a caracterização dos níveis em que estes se encontram é de grande importância para nortear o planejamento, constituindo-se como uma ferramenta importante para os tomadores de decisão uma vez que pode auxiliar, na execução de projetos de recuperação, além da identificação de áreas prioritárias para intervenção (ALMEIDA et al., 2019).

Para estudos voltados às análises ambientais, incluindo os processos de degradação do solo, o uso de geotecnologias constitui-se uma aliada (BATISTELLA et al., 2011). Essas ferramentas têm contribuído para a realização de pesquisas cada vez mais avançadas, com desenvolvimento de algoritmos de processamento digital de imagens mais eficazes e sensores mais poderosos que facilitam a obtenção de informações essenciais para o processo de análise ambiental (ALMEIDA et al., 2019).

No caso do planejamento da produção animal, o uso dessas técnicas pode contribuir na identificação e quantificação de eventuais processos de degradação de pastagens por meio da aplicação de índices de vegetação. Esses índices permitem analisar a variabilidade espacial e temporal do crescimento de pastagens além da condição fenológica da vegetação em função da sua variação espectral correlacionada com parâmetros biofísicos (FERREIRA; FERREIRA NETO, 2018).

Nesse contexto, o objetivo do artigo é caracterizar os níveis de degradação das áreas de pastagem do município mato-grossense de Araputanga. Considera-se que o apontamento e o diagnóstico do estado de conservação ambiental das pastagens na municipalidade são importantes e necessários podendo colaborar na ampliação de discussões sobre a temática, além de fornecem subsídios para o planejamento ambiental.

\section{MATERIAL E MÉTODOS}

\section{Área de estudo}

$\mathrm{O}$ município de Araputanga possui área de 1.600,24 $\mathrm{km}^{2}$ e integra a região de planejamento do Sudoeste do Estado de Mato Grosso (MATO GROSSO, 2017) (Figura 1). A população municipal é de 15.342 habitantes, dos quais $80,40 \%$ vivem na área urbana e 19,60\% na rural. O Índice de Desenvolvimento Humano Municipal (IDH-M) é de 0,725 (BRASIL, 2018). A economia de Araputanga e região é baseada na atividade pecuária, que 
consiste em um conjunto de atividades primárias, diretamente associadas à agricultura e à criação de animais (LUZ et al., 2017).

Figura 1 - Localização do município mato-grossense de Araputanga

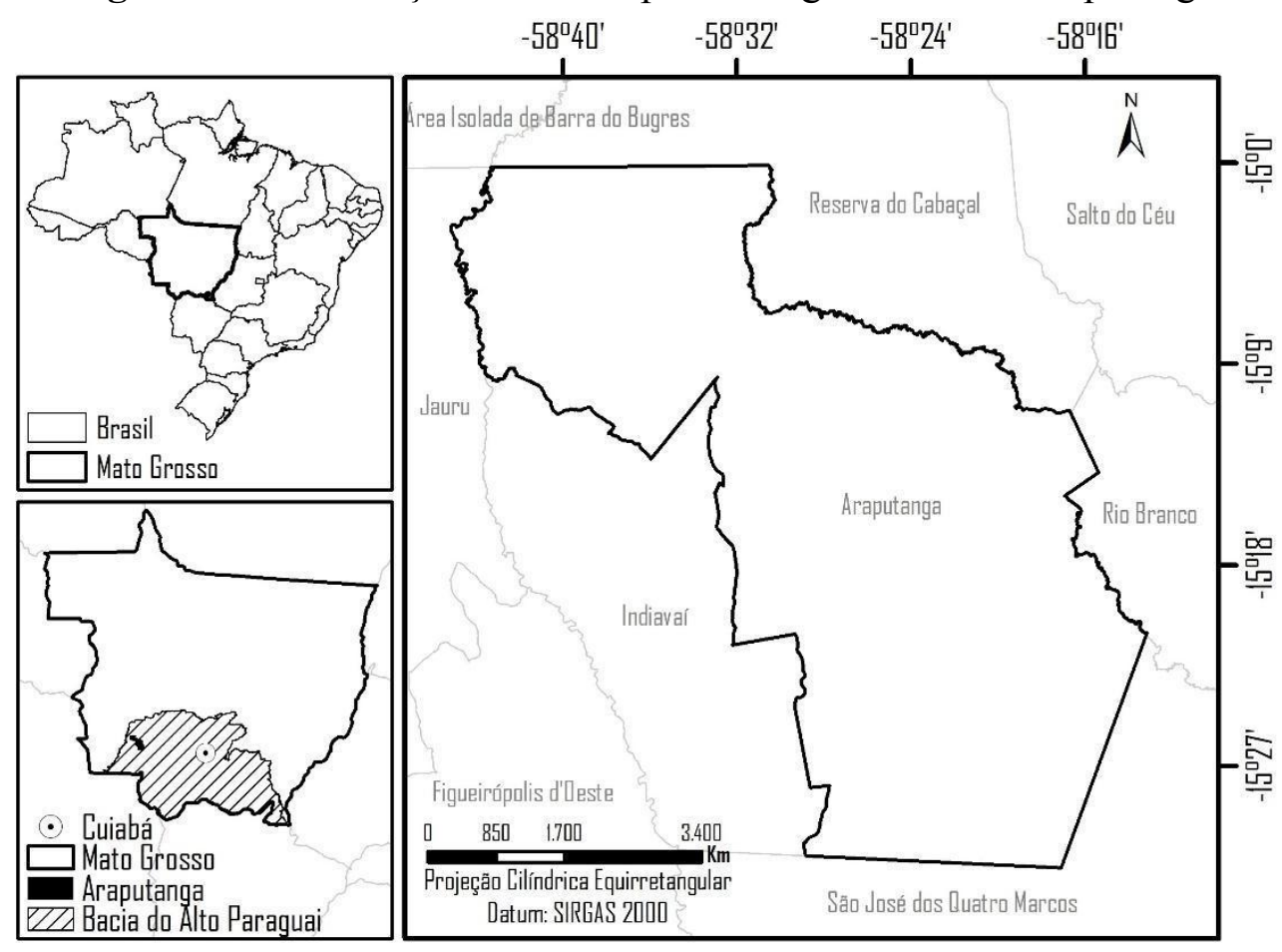

Bases cartográficas: IBGE (2016)

Fonte: Autores (2021)

Araputanga está inserido nos biomas Cerrado (16,26\%) e Amazônia (83,74\%). O clima da região é o Tropical úmido megatérmico do Baixo Planalto Jauru-Rio Branco e Depressões, com temperaturas médias anuais acima de $25{ }^{\circ} \mathrm{C}$ e precipitação total que varia entre 1400 e 1600 mm (LUZ et al., 2017). Suas principais características são duas estações bem definidas: seca e chuvosa. O município está inserido em cinco unidades morfoesculturais: (1) Planalto e Chapada dos Parecis, na porção meridional e extremo norte do município, respectivamente; (2) Planalto Dissecado dos Parecis, no terço médio da área; no sul do município, (3) a Depressão do Alto Paraguai e (4) Planaltos Residuais, além das (5) Planícies Aluvionares (PETRI; FÚLFARO, 1981).

\section{Procedimentos metodológicos}

Para elaboração do mapa pedológico foi utilizada a base cartográfica, em escala 1:250.000, do Diagnóstico Socioeconômico-Ecológico do Estado de Mato Grosso (DSEE-MT, 2000). No software ArcGis versão 10.5, procedeu-se o recorte da área de estudo 
bem como a atualização da nomenclatura dos tipos de solos atualizadas conforme o Sistema Brasileiro de Classificação de Solos (SANTOS et al., 2018).

O mapa de declividade foi elaborado por meio do Modelo Digital de Elevação (MDE), gerado a partir do radar interferométrico Shuttle Radar Topography Mission (SRTM), banda C, com resolução espacial de 30 metros, obtido gratuitamente no sítio da Global Land Cover Facility. O processamento digital das cenas incluiu a geração do mosaico, verificação de inexistência de valores de altitudes e conversão de projeção. A declividade foi classificada conforme as classes do IBGE (2009): declividade de 0 a 3\% - relevo plano; de 3 a $8 \%$ - relevo suave ondulado; 8 a 20\% - relevo ondulado; de 20 a 45\% - relevo forte ondulado; 45 a $75 \%$ relevo montanhoso; e $>75 \%$ - relevo escarpado (IBGE, 2009).

Para a geração dos dados de cobertura vegetal e uso da terra foram adquiridas, no sítio do Serviço Geológico Americano (USGS, 2016), imagens do satélite Landsat 8, de 2020, Órbita 228, Pontos 70 e 71 , com resolução espacial de 30 metros. Foram realizados os seguintes procedimentos: recorte, segmentação, classificação supervisionada no software Spring (CÂMARA et al., 1996), versão 5.5.3, e pós-classificação no ArcGis (ESRI, 2017). O recorte foi feito utilizando a base cartográfica digital do município como máscara.

$\mathrm{Na}$ segmentação foi adotado o método de crescimento de região, cujos valores de similaridade e de área definidos foi de 50. Segundo Dlugosz et al. (2009, p. 133), a similaridade é o limiar que corresponde "[...] à proximidade radiométrica entre pixels, correspondendo ao valor da distância euclidiana mínima entre as médias das regiões, abaixo do qual duas regiões são consideradas similares e, então, agrupadas". Se tratando do limiar de área, os mesmos autores explicam que este "[...] é o número mínimo de pixels para que uma região seja individualizada, sendo, portanto, o tamanho mínimo que cada segmento/polígono deve possuir na operação de segmentação" (DLUGOSZ et al., 2009, p. 133).

O classificador utilizado para foi Bhattacharya, com um limite de aceitação de 99,99\%. Posteriormente foram separadas apenas as áreas de pastagem para avaliação, sendo exportado o arquivo resultante no formato vetorial.

Para a estimativa da Cobertura Vegetal da Pastagem (CVP) e do Índice de Degradação de Pastagem (IDP), inicialmente foi calculado o Índice de Vegetação por Diferença Normalizada (NDVI) para cada pixel da imagem, desenvolvida por Rouse et al. (1973), dado pela Equação 1:

$$
N D V I=\frac{(I V P-V)}{(I V P+V)}
$$

onde:

IVP = banda do espectro Infravermelho Próximo; 
$V=$ banda do espectro Vermelho.

Em seguida, os valores de NDVI foram utilizados na obtenção do CVP (Equação 2) da área correspondente a cada pixel da imagem (GAO et al., 2006):

$$
C V P=\frac{\left(N D V I-N D V I_{s}\right)}{\left(N D V I_{v}-N D V I_{s}\right)} \times 100 \%
$$

onde:

NDVIs $=$ menor valor de NDVI encontrado entre os pixels representativos de áreas com solo exposto;

$N D V I v=$ maior valor de NDVI encontrado entre os pixels da área de pastagem.

Quatro classes de nível de degradação de pastagem foram definidas com base no CVP: (1) pastagem não-degradada (CVP > 60\%), (2) pastagem levemente degradada (CVP entre 50 e 60\%), (3) pastagem moderadamente degradada (CVP entre 40 e 50\%) e (4) pastagem fortemente degradada (CVP < 40\%) (ANDRADE et al., 2013). Essas classes foram utilizadas como parâmetros de entrada na Equação 3 para o cálculo do IDP (ANDRADE et al., 2013), adaptado de Gao et al. (2006):

$$
I D P=\frac{\sum_{i=1}^{4} D i \times A_{i}}{A}
$$

Onde:

$D i=$ número da classe de degradação;

$A i$ = área de distribuição do nível de classificação i;

$A=$ área total de pastagens da área.

Subsequentemente os dados em formato matricial foram convertidos para formato vetorial, sendo calculados as áreas correspondentes às classes e elaboradas as representações cartográficas.

\section{RESULTADOS E DISCUSSÃO}

O município de Araputanga apresentou 1051,58 km², dos seus 1.600,24 km² de área territorial, ocupado por áreas de pastagem, o que representa 65,71\%. As pastagens são cultivadas predominantemente nos Luvissolos $\left(984,89 \mathrm{~km}^{2}\right.$ ), ocupando $812,09 \mathrm{~km}^{2}$ destes 
(Figura 2). Esse tipo de solo varia de bem a pouco drenado, apresentando normalmente pouca profundidade (60 a $120 \mathrm{~cm}$ ), com sequência de horizontes $\mathrm{A}$, Bt e $\mathrm{C}$ e nítida diferenciação entre os horizontes $\mathrm{A}$ e $\mathrm{Bt}$, devido ao contraste de textura, cor e/ou estrutura entre eles (SANTOS et al., 2018).

Conforme Bertol et al. (2000), os Luvissolos apresentam pouca tolerância aos processos erosivos devido à baixa profundidade efetiva em que a relação taxa infiltração/deflúvio superficial é favorável ao aumento do risco de erosão.

Figura 2 - Classes de solo do município de Araputanga-MT

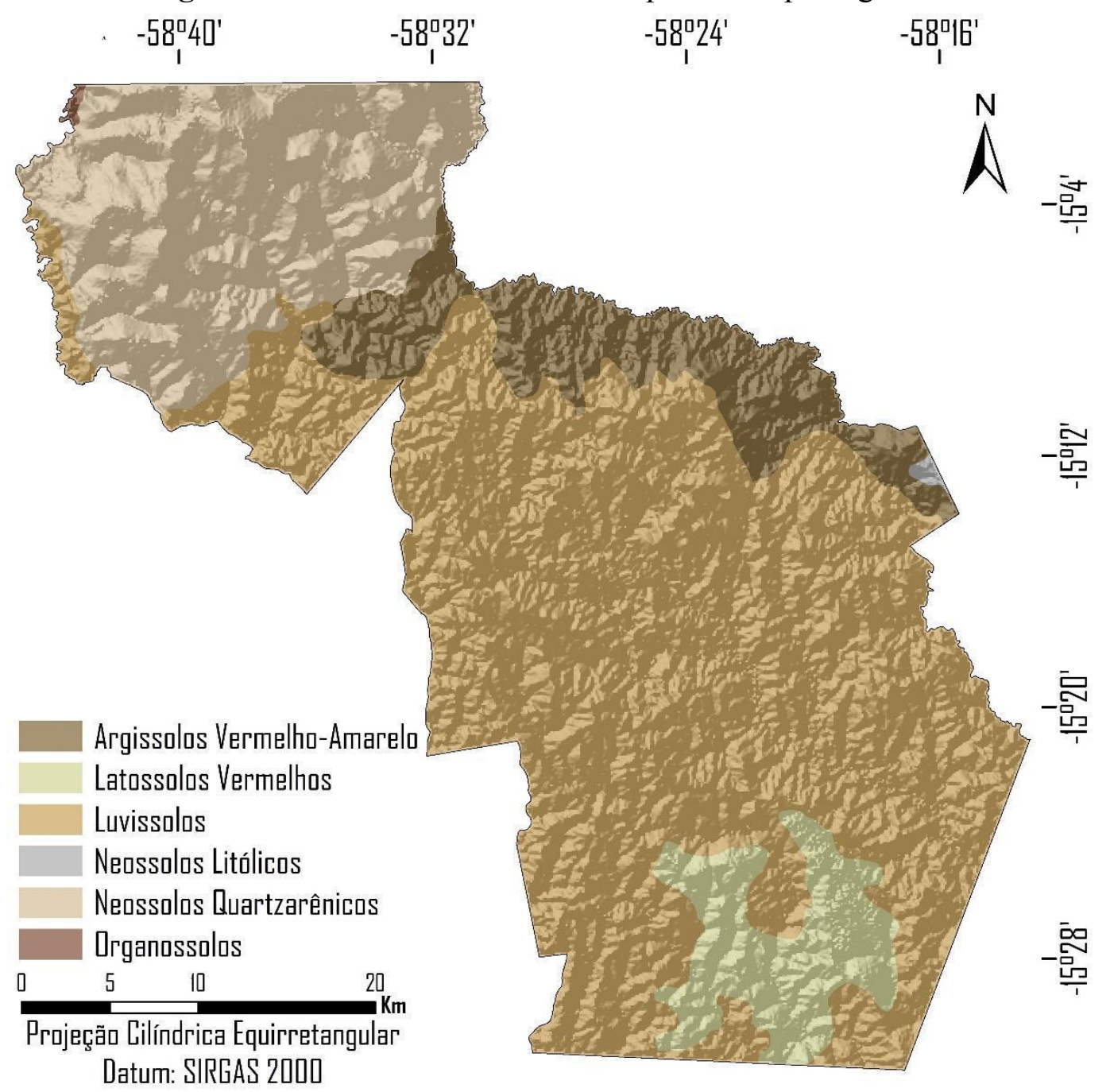

Bases cartográficas: IBGE (2016) e SEPLAG-MT (2019)

Fonte: Autores (2021)

Os Argissolos Vermelho-Amarelo $\left(164,55 \mathrm{~km}^{2}\right)$ apresentaram 109,26 km² de pastagem em sua área. Sendo solos muito erodíveis, principalmente devido às suas condições físicas 
intrínsecas, como o gradiente de textura entre os horizontes superficiais e subsuperficiais (SANTOS et al., 2018). Os Argissolos apresentam também forte erodibilidade, que é definida por Fernandes (2011) como a maior ou menor propensão natural com que suas partículas do solo são destacadas e transportadas pela ação de um agente erosivo, ou seja, indica a resistência do solo ao impacto das chuvas. Estes também tendem a ocupar locais com declividades mais acentuadas.

Os Argissolos são resultados do processo de podzolização, apresentam translocação de argila entre os horizontes superficiais e profundos e são formados em ambientes com condições cíclicas do clima (estações secas e úmidas definidas). Desse processo é característico a formação de horizonte B textural - Bt que expressa alta relação textural entre os horizontes A e B, conforme Santos et al. (2018). Essa classe apresenta também alta concentração de argila em subsuperfície, menor grau de floculação e menor porosidade no horizonte B. Muggler et al. (1996) explicam que, o movimento descendente da argila no perfil, favorece o entupimento de macroporos no horizonte Bt. Assim, essas características em conjunto favorecem a redução da velocidade da infiltração e, consequentemente, o acúmulo de água em subsuperfície bem como o aumento da atuação dos processos erosivos. Quando apresentam horizonte A arenoso, ou aumento abrupto de argila em profundidade se mostram como moderado a fortemente exposto às condições de erosão.

Os Latossolos Vermelhos ocupam 112,03 $\mathrm{km}^{2}$ do município apresentando grande profundidade, homogeneidade, boa drenagem e geralmente baixa fertilidade natural, necessitando de correções químicas para aproveitamento agrícola (SANTOS et al., 2018), $97,62 \mathrm{~km}^{2}$ desses solos são ocupados pelas pastagens. Os Latossolos são conhecidos por apresentarem baixo gradiente textural, alto grau de intemperismo e de desenvolvimento, elevada porosidade e friabilidade, sendo, portanto, altamente permeáveis (bem estruturados compostos de agregados granulares) (SANTOS et al., 2018). Muggler et al. (1996) destacam que, essas características, juntamente com o fato de que os Latossolos se situarem preferencialmente em relevos planos, favorecem a infiltração de água reduzindo o volume de escoamento superficial e, por conseguinte, a erosão.

Os Neossolos possuem, geralmente, baixa profundidade e horizonte A desenvolvido sobre rocha ou horizonte $\mathrm{C}$. A textura de areia e mineiras primários, além de baixos índices de argila, conferem fraca agregação das partículas atribuindo a estes solos alta exposição aos processos erosivos. Os Neossolos podem ser classificados a partir do $2^{\circ}$ nível categórico, conforme Santos et al. (2018), em Litólicos, Flúvicos, Regolíticos e Quartzarênicos.

No estudo em questão, os Neossolos Quartzarênicos $\left(334,87 \mathrm{~km}^{2}\right)$ tiveram $31,58 \mathrm{~km}^{2}$ ocupados por pastagens e os Neossolos Litólicos $\left(2,26 \mathrm{~km}^{2}\right)$ tiveram 1,00 $\mathrm{km}^{2}$ utilizado para a mesma atividade. Por serem pouco desenvolvidos, essa categoria tem "[...] severas limitações ao uso agrícola, seja pela textura muito arenosa, fertilidade muito baixa, ou ainda devido ao alumínio em níveis de toxicidade, baixa capacidade de retenção de água ou elevada suscetibilidade à erosão" (COELHO et al., 2002, p. 7). 
Os Organossolos $\left(1,64 \mathrm{~km}^{2}\right)$, que possuem alto teor de matéria orgânica, apresentaram baixa ocupação pelas pastagens $\left(0,03 \mathrm{~km}^{2}\right)$ devido à presença restrita dessa classe na área de pesquisa.

No tocante às classes de declividade, a predominante no município é a classe suave ondulado, ocorrendo em 47,01\% $\left(752,20 \mathrm{~km}^{2}\right)$ da área, sendo destas $69,76 \%\left(524,74 \mathrm{~km}^{2}\right)$ ocupada por pastagens, seguida de relevo plano, com $28,17 \%\left(450,79 \mathrm{~km}^{2}\right)$ sendo $32,98 \%$ $\left(148,65 \mathrm{~km}^{2}\right)$ de pastagem, e ondulado, com 22,45\% (359,33 $\left.\mathrm{km}^{2}\right)$ sendo 97,15\% $(349,08$ $\left.\mathrm{km}^{2}\right)$ pastagem, as demais classes ocupam 2,37\% $\left(37,93 \mathrm{~km}^{2}\right)$ da área de estudo (Figura 3).

Figura 3 - Classes de declividade do município de Araputanga-MT

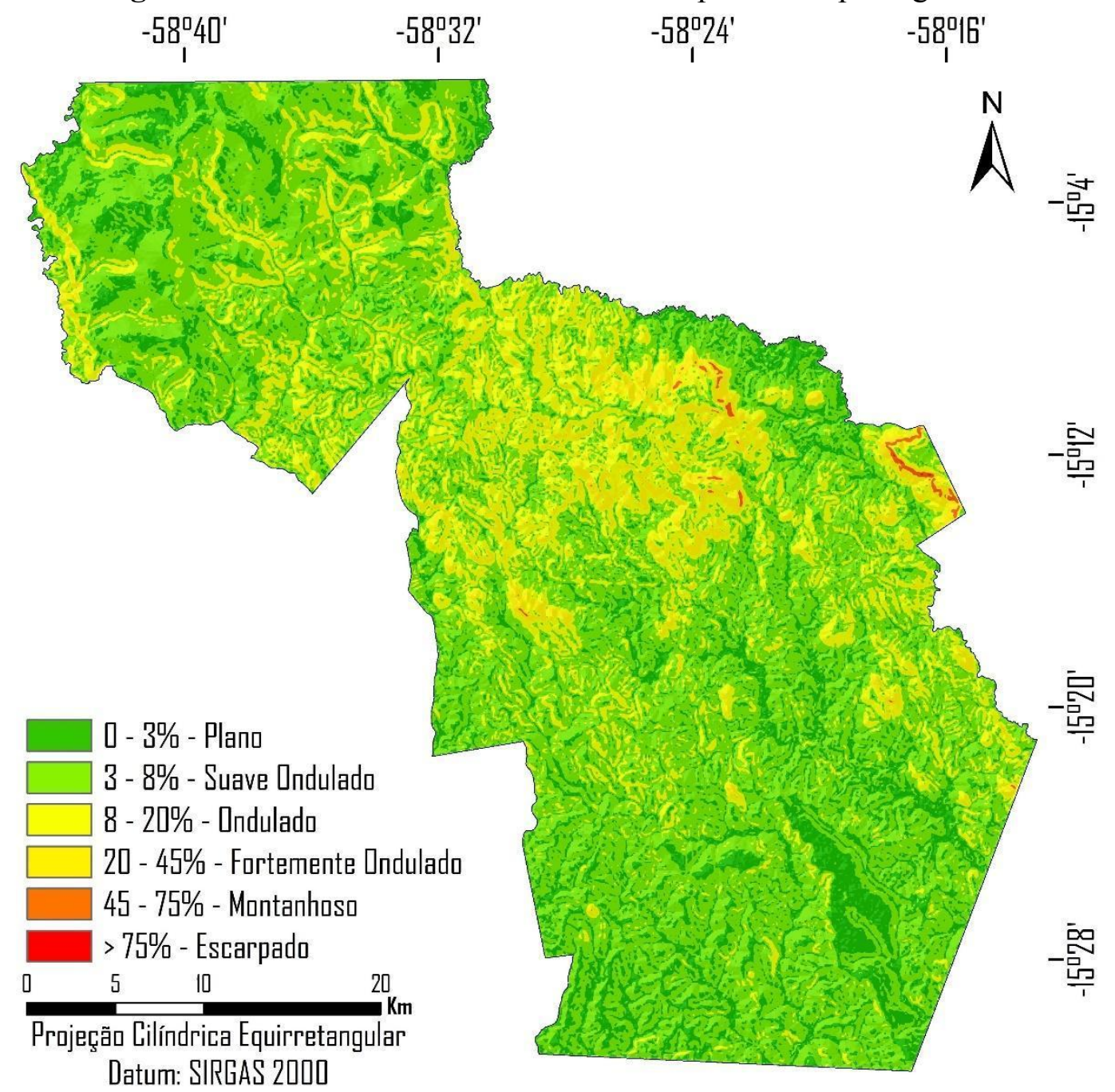

Bases cartográficas: IBGE (2016) e USGS (2016)

Fonte: Autores (2021) 
Segundo Cogo et al. (2003), o relevo é um fator que influencia fortemente as perdas de solo devido à erosão hídrica, dado que, com o aumento da declividade há uma ampliação da capacidade de transporte de partículas, reduzindo a infiltração de água no solo, o que associado a conversão da cobertura vegetal nativa em áreas de pastagens desencadeia uma série de alterações nas propriedades físicas e químicas do solo, que podem acelerar o processo de degradação, podendo ainda ser potencializado pelo tipo de solo e o sistema de manejo (ROSA et al., 2014).

Em súmula, pode-se considerar que solos rasos terão condições de acelerado encharcamento, devido pouca profundidade e baixo desenvolvimento estrutural, facilitando o processo de escoamento superficial e, por conseguinte, o arraste de partículas do horizonte superficial.

Ao contrário de solos mais jovens e rasos, conforme destacado por Resende (2007) e Reis et al. (2006), solos maduros, altamente intemperizados, tendem ao aumento da profundidade, porosidade, grau de agregação e teor significativo de silte e argila que, por consequência promovem maior resistência aos processos erosivos por afetarem de maneira direta a capacidade de infiltração e escoamento superficial.

Pode-se considerar a determinação de classes de permeabilidade do solo em função da textura e do grau de estrutura, dessa forma a Tabela 1 suporta as justificativas para a determinação de resistência a erosão em solos considerando os elementos de textura e grau de estrutura a partir da relação com permeabilidade de solos (GALINDO; MARGOLIS, 1989 apud OLIVEIRA et al., 2008, p. 63).

$\underline{\text { Tabela } 1 \text { - Classes de permeabilidade do solo em função da textura e grau de estrutura }}$

\begin{tabular}{ccc}
\hline Textura & Grau de Estrutura & $\begin{array}{c}\text { Classe de } \\
\text { Permeabilidade }\end{array}$ \\
\hline $\begin{array}{c}\text { Argilosa e muito argilosa } \\
(\text { argila } \geq 35 \%)\end{array}$ & Fraca/ Moderada/Forte & Lenta/ Lenta/Moderada \\
\hline $\begin{array}{c}\text { Média } \\
(15 \% \leq \text { argila } \leq 35 \%)\end{array}$ & Fraca/ Moderada/Forte & $\begin{array}{c}\text { Moderada/ } \\
\text { Moderada/Rápida }\end{array}$ \\
\hline $\begin{array}{c}\text { Arenosa } \\
\text { argila }+ \text { silte } \leq 15 \%\end{array}$ & Fraca/ Moderada/Forte & $\begin{array}{c}\text { Moderada/ } \\
\text { Rápida/Rápida }\end{array}$ \\
\hline
\end{tabular}

Fonte: Adaptado de Galindo (1989) apud Oliveira et al (2008, p. 63).

As características ambientais predominantes dos solos da área de estudo indicam que estes são altamente suscetíveis a processos erosivos em função dos atributos físicos da região, o que é agravado pelo desenvolvimento das atividades agropecuárias que desencadeiam mudanças na dinâmica natural do ambiente e dos componentes da paisagem (LUZ et al., 2017). 
Das áreas de pastagem de Araputanga 36,24\% (381,08 $\left.\mathrm{km}^{2}\right)$ apresentaram nível fortemente degradado (Figura 4), correspondendo às áreas com baixo vigor e qualidade, associada com a presença de plantas invasoras e áreas de solo descoberto.

Figura 4 - Níveis de degradação das pastagens no município de Araputanga-MT

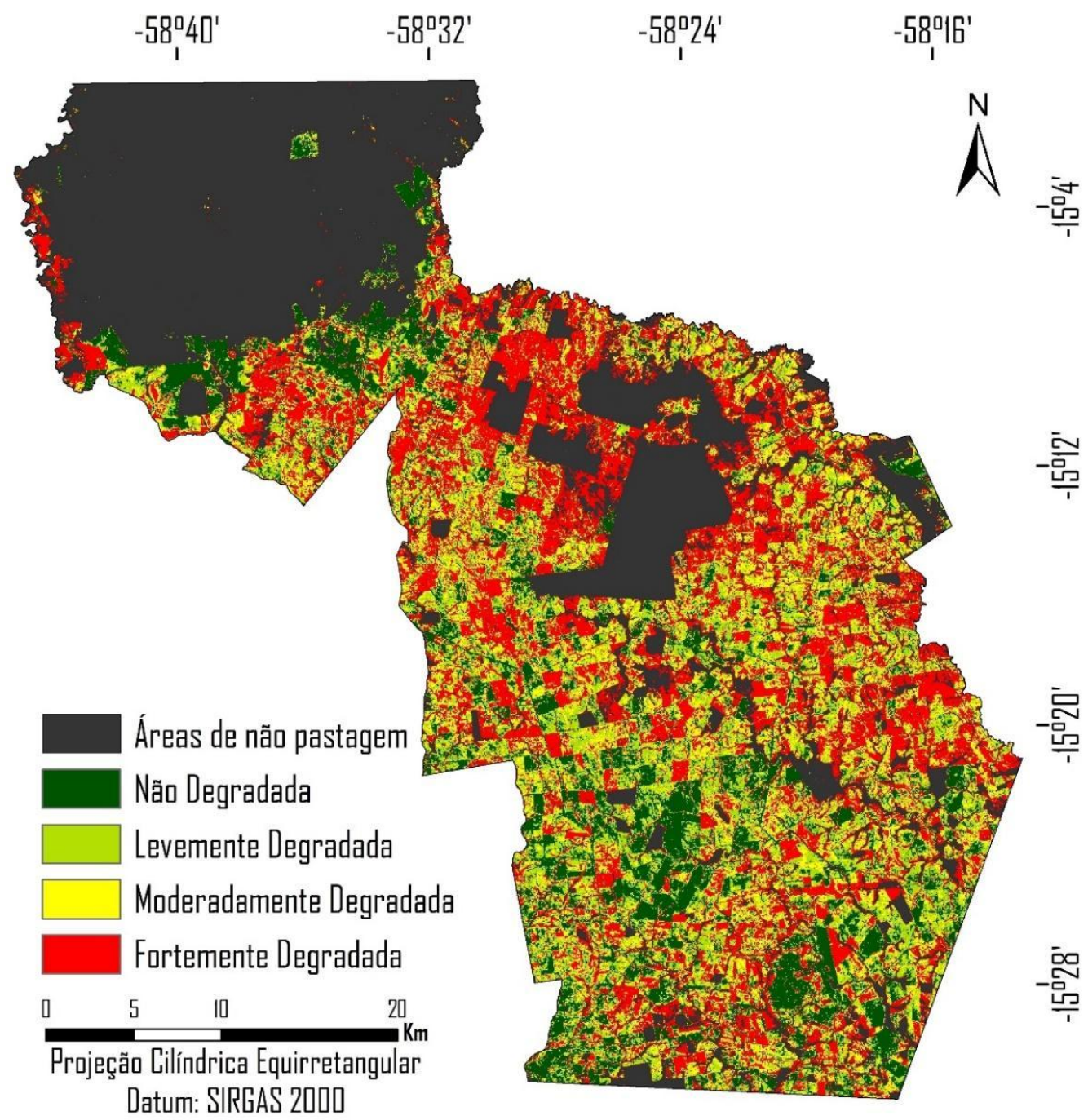

Bases cartográficas: IBGE (2016)

Fonte: Autores (2021)

As extensões territoriais com cultivo de pastagens do município moderadamente degradadas corresponderam a 22,36\% $\left(235,15 \mathrm{~km}^{2}\right)$, apresentando pastagens com baixo vigor e qualidade, associada com a presença de plantas invasoras, o que para Dias-Filho (2014) resulta na diminuição da produtividade agrícola e na capacidade de suporte que seria esperada nessas localidades. Esses fatores aliados a um manejo inadequado do solo e a lotação animal, podem atuar como aceleradores do processo de degradação. 
A classe levemente degradada, em que as pastagens apresentam baixo vigor e baixa qualidade sem a presença de invasoras, representou $21,18 \%\left(222,76 \mathrm{~km}^{2}\right)$, ocupando principalmente as áreas com relevo suave ondulado e ondulado. Para Freitas et al. (2016) este fator constitui um problema, pois não garante uma cobertura eficaz do solo, e quando desenvolvido em locais com declividades acentuadas, como em alguns pontos identificados, é necessária uma rápida intervenção por meio de práticas de conservação e de recuperação, contribuindo para redução das inadequações de uso proveniente dos processos de ocupação sem ordenamento.

Por fim, 20,22\% $\left(212,59 \mathrm{~km}^{2}\right)$ das pastagens não se encontram em nenhum estágio de degradação, apresentando bom vigor e boa qualidade.

A análise da Tabela 2 e da Figura 5 mostram que, dos $812,09 \mathrm{~km}^{2}$ de pastagens presentes nos Luvissolos $665,91 \mathrm{~km}^{2}(63,33 \%)$ possuem algum nível de degradação. Destes $28,16 \%\left(296,12 \mathrm{~km}^{2}\right)$ apresentam nível fortemente degradado, a maior porcentagem em comparação a área relativa das demais classes pedológicas. Fato preocupante devido às características físicas deste solo, citadas anteriormente.

Tabela 2 - Ocorrência de níveis de degradação $\left(\mathrm{km}^{2}\right)$ por classe pedológica

\begin{tabular}{|c|c|c|c|}
\hline Classe Pedológica & Nível de Degradação & $\begin{array}{r}\text { Área } \\
\left(\mathbf{k m}^{2}\right)\end{array}$ & $\%$ \\
\hline \multirow{5}{*}{ Argissolos Vermelho-Amarelo } & Não Degradada & 19,85 & 1,89 \\
\hline & Levemente Degradada & 16,59 & 1,58 \\
\hline & Moderadamente Degradada & 23,38 & 2,22 \\
\hline & Fortemente Degradada & 49,45 & 4,70 \\
\hline & Total & 109,26 & 10,39 \\
\hline \multirow{5}{*}{ Latossolos Vermelhos } & Não Degradada & 29,87 & 2,84 \\
\hline & Levemente Degradada & 18,80 & 1,79 \\
\hline & Moderadamente Degradada & 19,44 & 1,85 \\
\hline & Fortemente Degradada & 29,51 & 2,81 \\
\hline & Total & 97,62 & 9,28 \\
\hline \multirow{5}{*}{ Luvissolos } & Não Degradada & 146,18 & 13,90 \\
\hline & Levemente Degradada & 181,72 & 17,28 \\
\hline & Moderadamente Degradada & 188,08 & 17,89 \\
\hline & Fortemente Degradada & 296,12 & 28,16 \\
\hline & Total & 812,09 & 77,23 \\
\hline \multirow{5}{*}{ Neossolos Litólicos } & Não Degradada & 0,56 & 0,05 \\
\hline & Levemente Degradada & 0,19 & 0,02 \\
\hline & Moderadamente Degradada & 0,12 & 0,01 \\
\hline & Fortemente Degradada & 0,12 & 0,01 \\
\hline & Total & 1,00 & 0,09 \\
\hline & Não Degradada & 16,12 & 1,53 \\
\hline Neossolos Quartzarênicos & Levemente Degradada & 5,46 & 0,52 \\
\hline
\end{tabular}




\begin{tabular}{llrr}
\hline & Moderadamente Degradada & 4,13 & 0,39 \\
& Fortemente Degradada & 5,86 & 0,56 \\
\cline { 2 - 4 } & Total & $\mathbf{3 1 , 5 8}$ & $\mathbf{3 , 0 0}$ \\
\hline \multirow{4}{*}{ Organossolos } & Não Degradada & 0,00 & 0,00 \\
& Levemente Degradada & 0,01 & 0,00 \\
& Moderadamente Degradada & 0,01 & 0,00 \\
& Fortemente Degradada & 0,01 & 0,00 \\
\cline { 2 - 4 } & Total & $\mathbf{0 , 0 3}$ & $\mathbf{0 , 0 0}$ \\
\hline & Somatória Total & $\mathbf{1 0 5 1 , 5 8}$ & $\mathbf{1 0 0}$ \\
\hline
\end{tabular}

Fonte: Autores (2021)

Figura 5 - Ocorrência de níveis de degradação $\left(\mathrm{km}^{2}\right)$ por classe pedológica

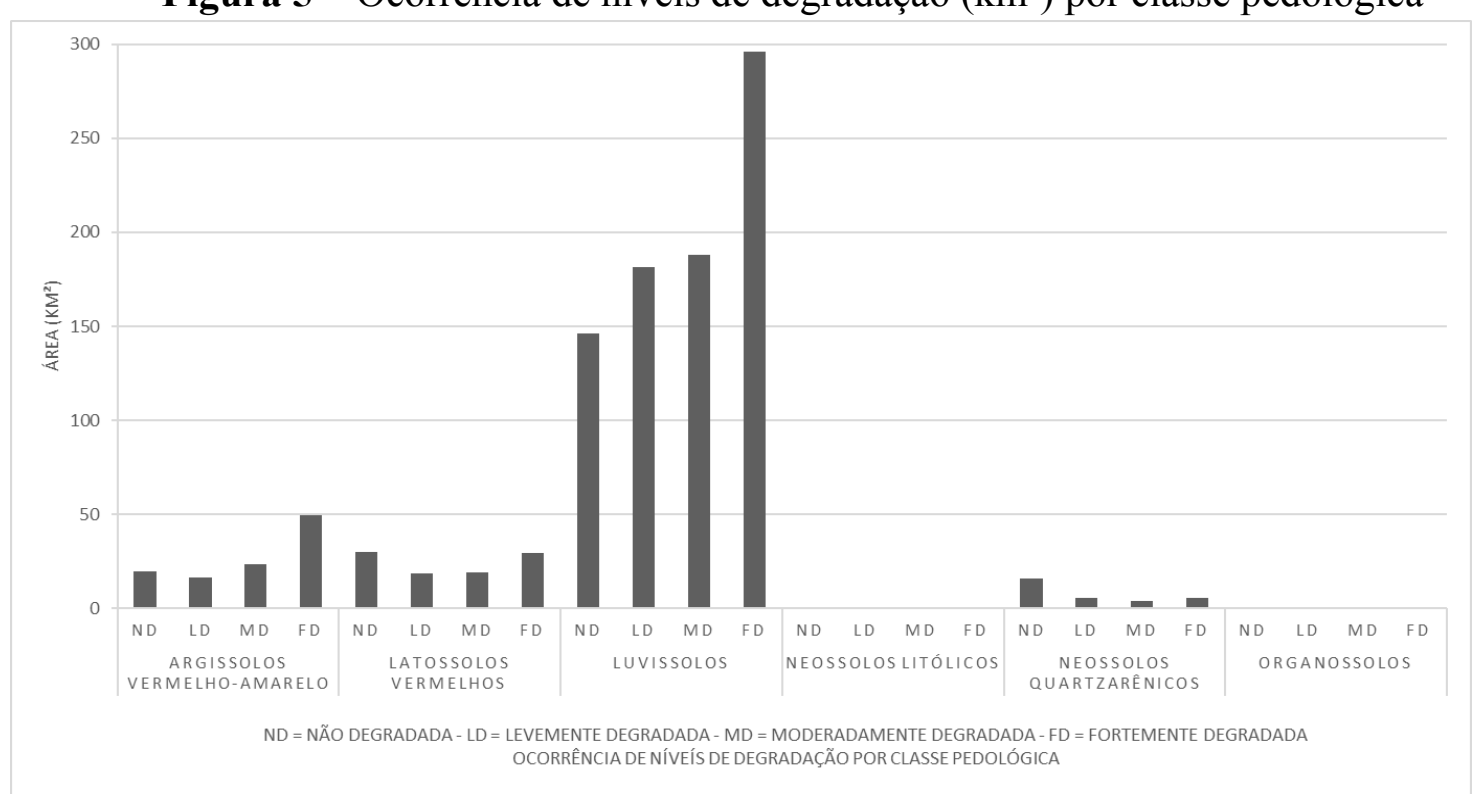

ND - Não Degradada; LD - Levemente Degradada; MD - Moderadamente Degradada; e FDFortemente Degradada

Fonte: Autores (2021)

Os Argissolos Vermelho-Amarelo apresentaram $84,41 \mathrm{~km}^{2}$ de pastagem em algum estágio de degradação. Destes, $296,12 \mathrm{~km}^{2}$ foram classificados como fortemente degradados, $188,08 \mathrm{~km}^{2}$ como moderadamente e $181,72 \mathrm{~km}^{2}$ como levemente.

Os Latossolos Vermelhos obtiveram $67,67 \mathrm{~km}^{2}$ de pastagens degradadas, sendo 29,51 $\mathrm{km}^{2}$ fortemente degradadas, $19,44 \mathrm{~km}^{2}$ moderadamente e $18,80 \mathrm{~km}^{2}$ levemente.

Os Neossolos Quartzarênicos e Litólicos apresentaram 15,46 km² e 0,44 km², respectivamente, de área de pastagem com algum nível de degradação. Os Organossolos foram inexpressivos dado sua representatividade na área de estudo.

Referente a declividade, a classe Suave Ondulado foi a que obteve maior área ocupada por pastagens $\left(524,74 \mathrm{~km}^{2}\right)$, sendo que $406,10 \mathrm{~km}^{2}$ apresentaram algum nível de degradação. 
Em segundo, a classe Ondulado (349,08 $\mathrm{km}^{2}$ ocupada por pastagens) teve $294,70 \mathrm{~km}^{2}$ de área de pastagem enquadrada como degradada. Em sequência, a classe Plano $\left(148,65 \mathrm{~km}^{2}\right.$ ocupada por pastagens) obteve $111,80 \mathrm{~km}^{2}$ de área degradada.

Em seguida ficaram as classes: Fortemente Ondulado $\left(28,09 \mathrm{~km}^{2}\right.$ ocupada por pastagens), Montanhoso (1,03 $\mathrm{km}^{2}$ ocupada por pastagens) e Escarpado (0,00 $\mathrm{km}^{2}$ ocupada por pastagens), com $25,46 \mathrm{~km}^{2}, 0,93 \mathrm{~km}^{2}$ e $0,00 \mathrm{~km}^{2}$ de área de pastagem com algum nível de degradação, respectivamente (Tabela 3 e Figura 6).

Tabela 3 - Ocorrência de níveis de degradação $\left(\mathrm{km}^{2}\right)$ das pastagens por classe de declividade

\begin{tabular}{|c|c|c|c|}
\hline Fase do Relevo & Nível de Degradação & Área $\left(\mathrm{km}^{2}\right)$ & $\%$ \\
\hline \multirow{5}{*}{ Plano } & Não Degradada & 36,84 & 3,50 \\
\hline & Levemente Degradada & 31,95 & 3,04 \\
\hline & Moderadamente Degradada & 30,90 & 2,94 \\
\hline & Fortemente Degradada & 48,96 & 4,66 \\
\hline & Total & 148,65 & 14,14 \\
\hline \multirow{5}{*}{ Suave Ondulado } & Não Degradada & 118,63 & 11,28 \\
\hline & Levemente Degradada & 117,17 & 11,14 \\
\hline & Moderadamente Degradada & 117,09 & 11,13 \\
\hline & Fortemente Degradada & 171,85 & 16,34 \\
\hline & Total & 524,74 & 49,90 \\
\hline \multirow{5}{*}{ Ondulado } & Não Degradada & 54,38 & 5,17 \\
\hline & Levemente Degradada & 69,58 & 6,62 \\
\hline & Moderadamente Degradada & 81,35 & 7,74 \\
\hline & Fortemente Degradada & 143,76 & 13,67 \\
\hline & Total & 349,08 & $\overline{33,20}$ \\
\hline \multirow{5}{*}{ Fortemente Ondulado } & Não Degradada & 2,63 & 0,25 \\
\hline & Levemente Degradada & 3,99 & 0,38 \\
\hline & Moderadamente Degradada & 5,71 & 0,54 \\
\hline & Fortemente Degradada & 15,77 & 1,50 \\
\hline & Total & 28,09 & 2,67 \\
\hline \multirow{5}{*}{ Montanhoso } & Não Degradada & 0,10 & 0,01 \\
\hline & Levemente Degradada & 0,07 & 0,01 \\
\hline & Moderadamente Degradada & 0,11 & 0,01 \\
\hline & Fortemente Degradada & 0,74 & 0,07 \\
\hline & Total & $\mathbf{1 , 0 3}$ & 0,10 \\
\hline \multirow{6}{*}{ Escarpado } & Não Degradada & 0,00 & $\overline{0,00}$ \\
\hline & Levemente Degradada & 0,00 & 0,00 \\
\hline & Moderadamente Degradada & 0,00 & 0,00 \\
\hline & Fortemente Degradada & 0,00 & 0,00 \\
\hline & Total & $\mathbf{0 , 0 0}$ & $\overline{0,00}$ \\
\hline & Somatória Total & 1051,58 & 100 \\
\hline
\end{tabular}


Fonte: Autores (2021)

Figura 6 - Ocorrência de níveis de degradação $\left(\mathrm{km}^{2}\right)$ das pastagens por classe de declividade

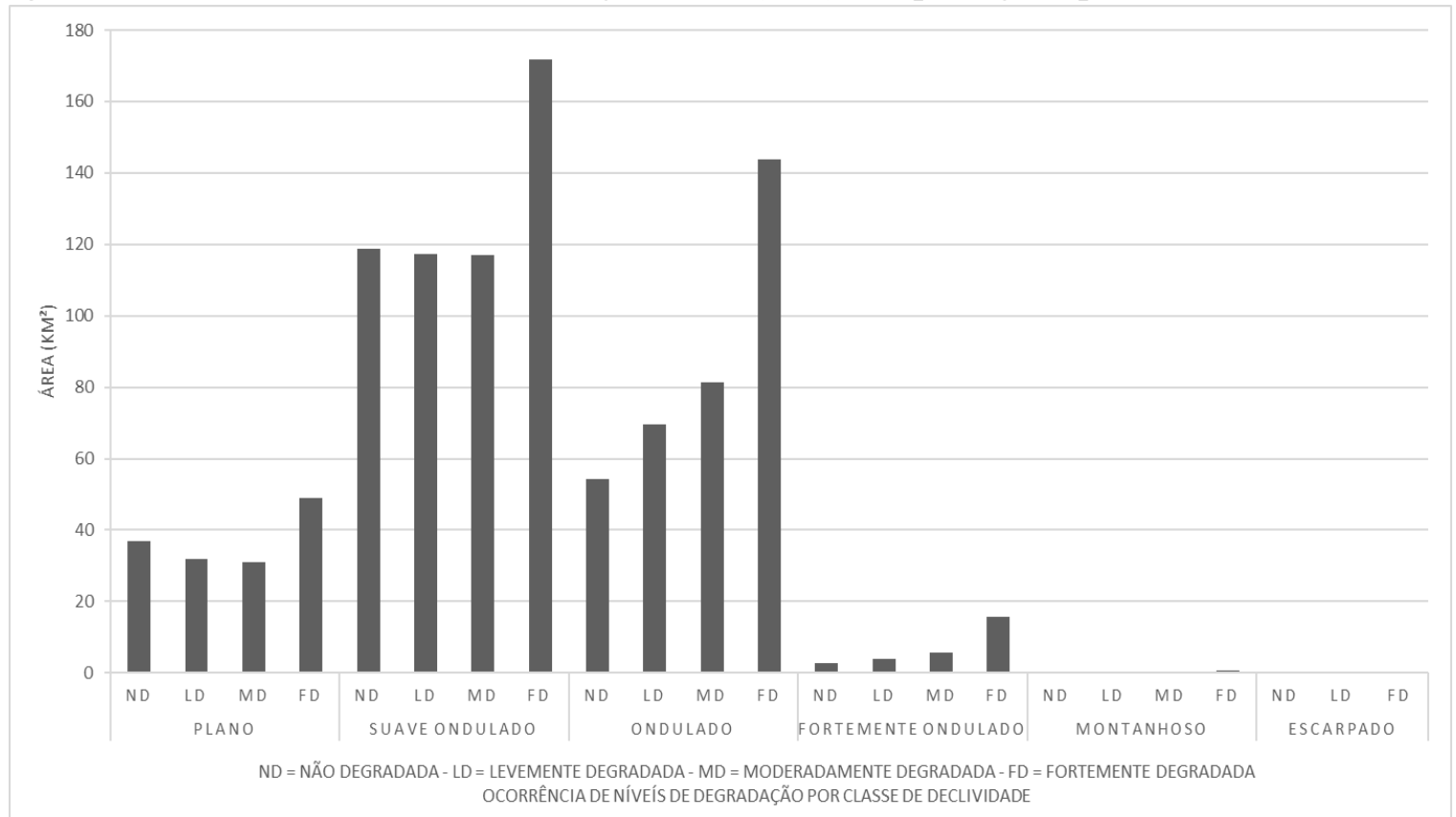

ND - Não Degradada; LD - Levemente Degradada; MD - Moderadamente Degradada; e FDFortemente Degradada

Fonte: Autores (2021)

O uso intensivo do solo em várias áreas do município, desconsiderando suas limitações ambientais pode comprometer sua capacidade produtiva, ocasionando diversos problemas, como o aceleramento dos processos erosivos, favorecido por sua predisposição ambiental (RAMOS et al., 2018). Nesse sentido, a degradação das pastagens, possui vários estágios, estão diretamente associados à erosão e perda de solos, conforme exemplificação da Figura 7.

Figura 7 - Representação gráfica do processo de degradação de pastagens cultivadas 


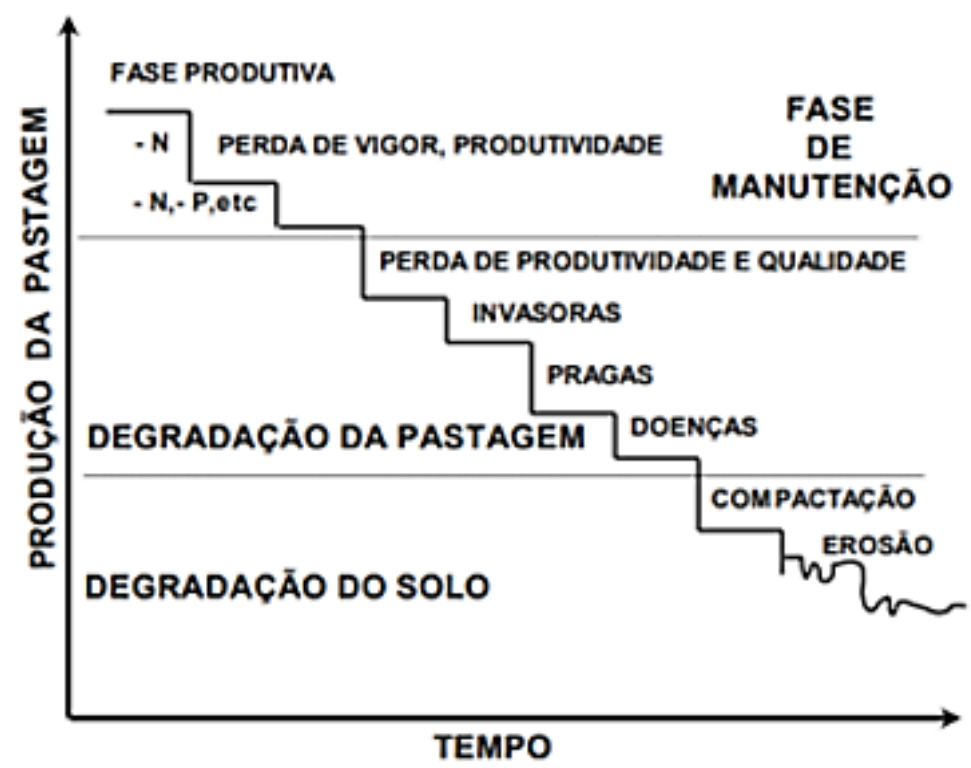

Fonte: Macedo (2001) apud Pereira et al. (2020)

A preocupação com o uso sustentável das pastagens, considerando tanto sua formação quanto recuperação, é um assunto estratégico para o país, pois a recuperação e o manejo adequado dessas áreas podem favorecer a queda do preço da carne e leite produzidos (ANDRADE et al., 2017; PEREIRA et al., 2020). Andrade et al. (2017) ressaltam a importância da restauração de pastagens no intuito de reduzir a pressão pela abertura de novas áreas em detrimento de outros espaços com cobertura de vegetação nativa. Assim, quando uma pastagem é recuperada há possibilidade de resgate da produtividade, mitigação de emissões dos gases do efeito estufa por meio do sequestro do dióxido de carbono atmosférico e preservação de mais carbono no solo. Portanto, é possível que a atividade pecuária alie sua produtividade a iniciativas sustentáveis.

Barbosa et al. (2015) enfatizam que tem sido atribuído à pecuária a intensificação do desmatamento no Brasil, mas que esta atividade precisa se adequar ao rigor das leis ambientais, além da competitividade com outras atividades como a cultura de soja, e procurar melhora o manejo de suas pastagens.

Vale ressaltar que o município de Araputanga está inserido em uma área com alto nível de prioridade para intensificação do rebanho bovino, como pode ser visto na Figura 8. A região, como outras do país encontra-se diante do paradoxo de aumentar o valor da produção e, ao mesmo tempo, diminuir os impactos ambientais provocados pela atividade pecuária.

Figura 8 - Níveis e áreas prioritárias para intensificação do rebanho bovino, no Mato Grosso, em função da redução de pastagens em decorrência da expansão agrícola, demografia do rebanho, logística aos principais frigoríficos e proximidade com áreas produtoras de grãos 


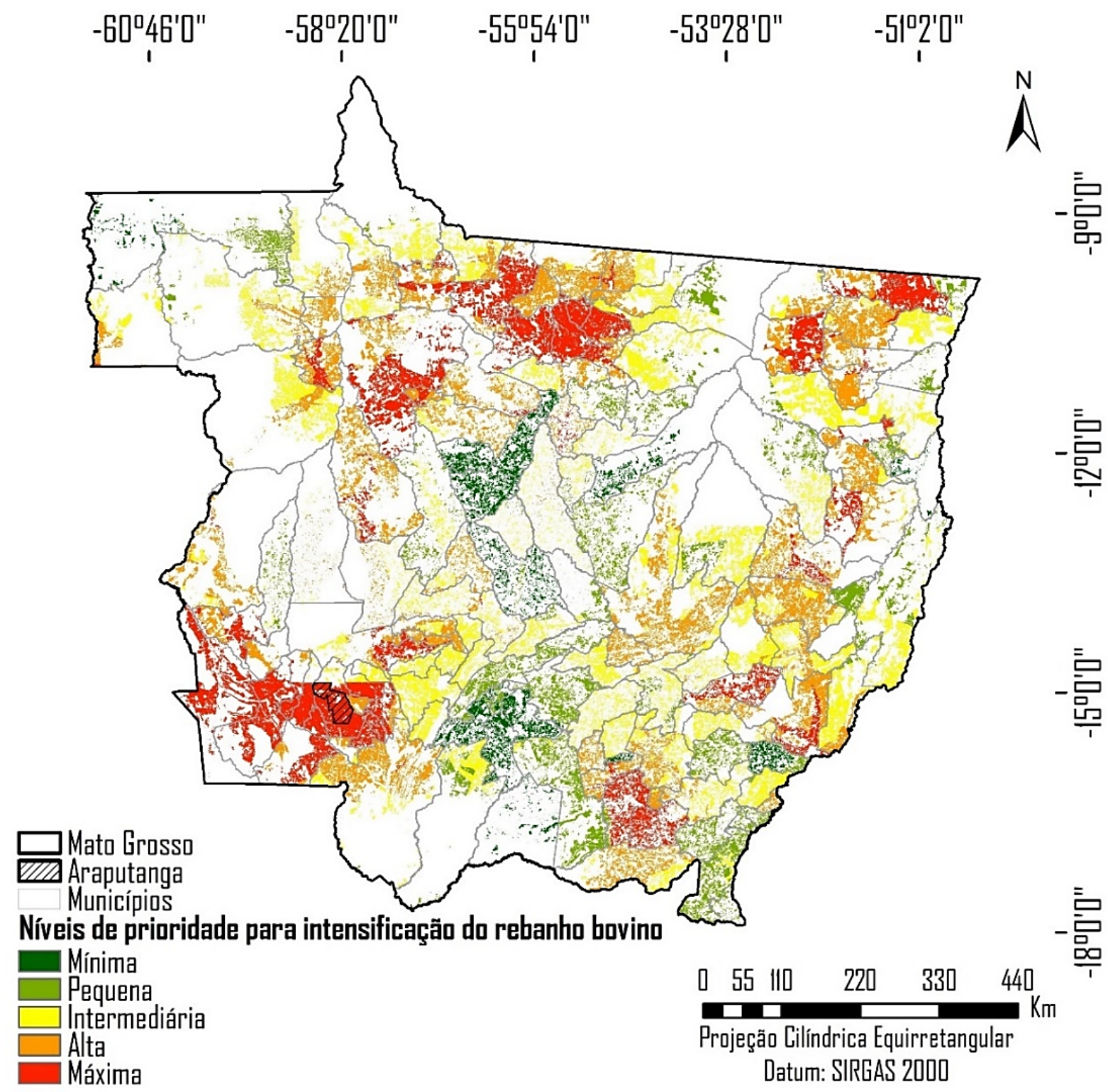

Bases cartográficas: IBGE (2016) e Barbosa et al. (2015)

Fonte: Adaptado de Barbosa et al. (2015)

Diante desse cenário os segmentos da sociedade e a gestão pública relacionados à atividade pecuária devem estar atentos e efetuar o monitoramento de forma periódica, em diversas escalas (municipal, regional e nacional), com a finalidade de evitar processos decorrentes das interferências antrópicas (LUZ et al., 2017). Para tanto, ferramentas baseadas em geotecnologias podem auxiliar na tomada de decisão e diretrizes de políticas públicas. Nesse sentido, o Índice de Cobertura Vegetal de Pastagem (CVP) mostrou-se uma ferramenta adequada para identificação e classificação da degradação da pastagem, principalmente em condições mais severas, contribuindo para estudos de planejamento e gestão ambiental (FERREIRA; FERREIRA NETO, 2018). 


\section{CONSIDERAÇÕES FINAIS}

Em Araputanga foram encontrados significativas áreas de pastagem em estágio avançado de degradação ou degradadas. Constatou-se que essa degradação é influenciada pelo tipo de solo, principalmente os Luvissolos e os Neossolos Quartzarênicos, caracterizado por alta erodibilidade natural, associados a relevos planos/ondulados, mas que tendem a ser fortemente marcados por erosões laminares.

Sugere-se o estabelecimento ou ampliação de práticas conservacionistas e a restauração das áreas com índices de degradação mais elevados, a qual a recuperação natural tende a ser mais difícil, visando o restabelecimento da produtividade, para que não seja necessário a ampliação do pasto, implicando na incorporação de novas áreas, principalmente aquelas recobertas com vegetação natural.

Para tanto, a recuperação das pastagens precisa ser entendida como investimento e não custo. Essa prática precisa ser estimulada e permear as políticas de incentivos e de gestão pública. Os "trade-offs" entre pastagem (formação, manejo e recuperação) e produtividade necessitam ser mais explorados incluindo práticas mais sustentáveis na atividade pecuária, o que representa um sistema de produção mais eficiente além de uma imagem positiva do país perante os compradores interacionais das commodities do setor.

A metodologia utilizada na pesquisa se mostrou satisfatória, pois permitiu concluir que a operacionalização do Índice de Degradação de Pastagem, por meio das geotecnologias, constitui uma ferramenta viável para o monitoramento e planejamento da utilização das pastagens, podendo contribuir para melhoria de desempenho da atividade agropecuária a um baixo custo e em seu monitoramento em diferentes esferas de interesse.

\section{AGRADECIMENTOS}

O presente trabalho foi realizado com apoio da Coordenação de Aperfeiçoamento de Pessoal de Nível Superior - Brasil (CAPES).

\section{REFERÊNCIAS}

ALMEIDA, M. B. F; SIMÕES, M.; FERRAZ, R. P. D. Aplicação de sensoriamento remoto no estudo dos níveis de degradação de pastagens. In: TULLIO, L. Aplicações e princípios de sensoriamento remoto 3. 1 ed. Ponta Grossa: Atena Editora, 2019. cap. 2, p. 11-21.

ANDRADE, R. G.; BOLFE, E. L.; VICTÓRIA, D. C.; NOGUEIRA, S. F. Avaliação das condições de pastagens no cerrado brasileiro por meio de geotecnologias. Revista Brasileira de Agropecuária Sustentável, Viçosa/MG, v. 7, n. 1, p. 34-41, 2017. 
ANDRADE, R. G.; RODRIGUES, G. A. C.; SANCHES, I. D. A.; TORRESAN, F. E.; QUARTAROLI, C. F. Uso de técnicas de sensoriamento remoto na detecção de processos de degradação de pastagens. Engenharia e Agricultura, Viçosa/MG, v. 21, n. 3, p. 234-243, 2013.

BARBOSA, F. A.; SOARES-FILHO, B. S.; MERRY, F. D.; AZEVEDO, H. O.; COSTA, W. L. S.; COE, M. T.; BATISTA, E. L. S.; MACIEL T. G.; SHEEPERS, A. R. O.; RODRIGUES, H. O. Cenários para a pecuária de corte amazônica. 1 ed. Belo Horizonte: CSR/IGC/UFMG, 2015. 146p.

BATISTELlA, M.; ANDRADE, R. G.; BOLFE, E. L.; VICTORIA, D. C.; SILVA, G. B. S. Geotecnologias e gestão territorial da bovinocultura no Brasil. Revista Brasileira de Zootecnia, Viçosa/MG, v. 40, n. Especial, p. 251-260, 2011.

BERTOL, I.; ALMEIDA, J. A. Tolerância de perda de solo por erosão para os principais solos do Estado de Santa Catarina. Revista Brasileira de Ciência do Solo, Viçosa/MG, v. 24, n. 3, p. 657-668, 2000.

CÂMARA, G.; SOUZA, R. C. M.; FREITAS, U. M.; GARRIDO, J. SPRING: Integrating remote sensingand GIS by object oriented data modelling. Computers \& Graphics, Oxford/UK, v. 20, n. 3, p. 395-403, 1996.

CARVAlHO, J. M.; NEVES, R. J.; SERAFIM, M. E.; NEVES, S. M. A. S.; KREITLOW, J. P.; FREITAS, L. E. Susceptibilidade e potencial atual à erosão hídrica dos solos na bacia hidrográfica do rio Cabaçal, Mato Grosso, Brasil. Revista Brasileira de Cartografia, Rio de Janeiro, v. 69, n. 9, p. 1655-1667, 2017.

COELHO, M. R.; SANTOS, H. G.; SILVA, E. F.; AGLIO, M. L. D. O recurso natural do solo. In: MANZATTO, C. V. Uso agrícola dos solos brasileiros. Rio de Janeiro: Embrapa Solos, 2002. cap. 1, p. 1-12.

COGO, N. P.; LEVIEN, R.; SCHWARZ, R. A. Perdas de solo e água por erosão hídrica influenciadas por métodos de preparo, classes de declive e níveis de fertilidade do solo. Revista Brasileira de Ciência do Solo, Viçosa/MG, v. 27, n. 4, p. 743-753, 2003.

DIAS-FILHO, M. B. Diagnóstico das pastagens no Brasil. 1 ed. Belém: Embrapa Amazônia Oriental, 2014. 36p.

DLUGOSZ, F. L.; ROSOT, N. C.; ROSOT, M. A. D.; OLIVEIRA, Y. M. M. Índice para a avaliação de segmentação de imagens. Floresta, Curitiba, v. 39, n. 1, p. 131-143, 2009.

ESRI. ArcGIS Desktop: release 10.5. Redlands, CA: Environmental Systems Research Institute, 2017.

FARIA, T. O.; VECCHIATO, A. B.; SALOMÃO, F. X. T.; SANTOS JR, W. A. Abordagem morfopedológica para diagnóstico e controle de processos erosivos. Revista Ambiente \& Água, Taubaté/SP, v. 8, n. 2, p. 215-232, 2013.

FERNANDES, J. A. Estudo da Erodibilidade de Solos e Rochas de uma Voçoroca em São Valentim, RS. $2011.127 \mathrm{f}$. Dissertação (Mestrado em Engenharia Civil) - Centro de Tecnologia, Universidade Federal de Santa Maria.

FERREIRA, G. C. V.; FERREIRA NETO, J. A. Usos de geoprocessamento na avaliação de degradação de pastagens no assentamento Ilha do Coco, Nova Xavantina - Mato Grosso, Brasil. Engenharia na Agricultura, Viçosa/MG, v. 26, n. 2, p. $140-148,2018$

FREITAS, G. A.; BENDITO, B. P. C.; SANTOS, A. C. M.; SOUSA, P. A. Diagnóstico ambiental de áreas de pastagens degradadas no município de Gurupi - TO. Biota Amazônica, Macapá, v. 6, n. 1, p. 10-15, 2016.

FREITAS, L. E.; NEVES, S. M. A. S.; NUNES, M. C. M.; CARVALHO, M. A. C.; LUZ, C. C. S. PAULA, D. G. Abordagem morfopedológica na avaliação da suscetibilidade à erosão dos solos em Vale de São Domingos (MT). Revista Ibero-Americana de Ciências Ambientais, Aracaju, v. 8, n. 1, p. 49-61, 2017.

GALDINO, S.; ARAÚJO, L. S.; SILVA, G. B. S; NOGUEIRA, S. F.; PEREIRA, K. C. Modelagem da erosão aplicada ao planejamento conservacionista do solo em pastagens de Pindamonhangaba, SP. 1 ed. Campinas: Embrapa Monitoramento por Satélite, 2014. 24p.

GALINDO, I. C. L.; MARGOLIS, E. Tolerância de perdas por erosão para solos do Estado de Pernambuco. Revista Brasileira de Ciência do Solo, Viçosa/MG, v. 13, n. 1, p. 95-100, 1989.

GAO, Q.; LI, Y.; WAN, Y.; LIN, E; XIONG, W.; JIANGCUN, W.; WANG, B.; LI, W. Grassland degradation in northern Tibet base on remote sensing data. Journal Geographical Sciences, Beijing/CN, v. 16, n. 2, p. 165-173, 2006. 
IBGE. Instituto Brasileiro de Geografia e Estatística. 2016. Malhas territoriais. Disponível em: $<$ https://www.ibge.gov.br/geociencias/organizacao-do-territorio/malhas-territoriais/15774-malhas.html?edicao=27413\&t=ace sso-ao-produto>.

IBGE. Instituto Brasileiro de Geografia e Estatística. Censo Demográfico - 2010. Rio de Janeiro: IBGE, 2018. Disponível em: <http://www.cidades.ibge.gov.br/v3/cidades/municipio/5101258>.

IBGE. Instituto Brasileiro de Geografia e Estatística. Manual Técnico de Geomorfologia. 2 ed. Rio de Janeiro: IBGE, 2009. $175 \mathrm{p}$.

LUZ, C. C. S.; BARROS, C. A.; NEVES, S. M. A. S.; NEVES, R. J.; NUNES, M. C. M. Diagnoses of potential erosion areas and land use conflicts in the Araputanga municipality, Mato Grosso State (MT), Brazil. GEOGRAFIA, Rio Claro/SP, v. 42, n. Especial, p. 71-86, 2017.

MACEDO, M. C. M. Integração lavoura e pecuária: alternativa para sustentabilidade da produção animal. In: SIMPÓSIO SOBREMANEJO DA PASTAGEM, 18., 2001, Piracicaba. Anais... Piracicaba: FEALQ, 2001. p. 257-283.

MATO GROSSO (Estado). Secretaria de Estado de Planejamento e Coordenação Geral. Plano de Longo Prazo de Mato Grosso: macro-objetivos, metas globais, eixos estratégicos e linhas estruturantes. 1 ed. Cuiabá: Central de Texto, 2017. 108p.

MATO GROSSO (Estado). Secretaria de Estado de Planejamento e Coordenação Geral. Sistema de Informações $\begin{array}{llllll}\text { Cartográficas da } & \text { SEPLAG-MT } & \text { (Base } & \text { Cartográfica). } & 2019 . & \text { Disponível em: }\end{array}$ $<$ http://www.seplan.mt.gov.br/-/10951338-bases-cartograficas?ciclo=cv_gestao_inf $>$.

MIRANDA, J. G. Mapeamento geotécnico e estudo da susceptibilidade à erosão na bacia do Ribeirão Ponte de Pedra (MT), escala 1: 100.000. 2005. 278 f. Tese (Doutorado em Geotecnia) - Escola de Engenharia de São Carlos, Universidade de São Paulo.

MUGGLER, C. C.; CURI, N.; SILVA, M. L. N.; LIMA, J. M. de. Características pedológicas de ambientes agrícolas nos chapadões do Rio Corrente, sudoeste da Bahia. Pesquisa Agropecuária Brasileira, Brasília, v. 31, n. 3, p. 221-232, 1996.

OLIVEIRA, F. P.; SANTOS, D.; SILVA, I. F.; SILVA, M. L. N. Tolerância de Perda de Solo por Erosão para o Estado da Paraíba. Revista de Biologia e Ciências da Terra, Sergipe, v. 8, n. 2, p. 60-71, 2008.

PEREIRA, M. A.; COSTA, F. P.; MONTAGNER, D.B.; EUCLIDES, V. P. B.; ARAÚJO, A. R.; BARBOSA, R. A.; SOUZA, J. A. B. A. Pastagens: condicionantes e seus efeitos nas decisões de formação e manejo. Campo Grande: Embrapa Gado de Corte, 2020. 24p.

PETRI, S.; FÚLFARO, J. V. Geologia da Chapada dos Parecis, Mato Grosso, Brasil. Revista Brasileira de Geociências, São Paulo, v. 11, n. 4, p. 274-282, 1981.

RAMOS, A. W. P.; LUZ, C. C. S.; NEVES, S. M. A. S.; FREITAS, L. E.; NEVES, L. F. S. Análise da capacidade e conflito de uso da terra na bacia hidrográfica do Córrego da Piraputanga-MT, Brasil. Caderno de Geografia, Belo Horizonte, v. 28, n. 55 , p. 812-827, 2018.

REIS, M. H.; GRIEBELER, N. P.; SOUZA, P. T. M.; RABELO, M. W. O. Mapeamento de áreas de risco à ocorrência da erosão hídrica no Sudoeste Goiano com base na distribuição espacial de chuvas intensas. In: SIMPÓSIO DE GEOTECNOLOGIAS NO PANTANAL. 1., 2006. Campo Grande. Anais... São José dos Campos: INPE, 2009. p. 219-228.

RESENDE, M.; CURI, N.; REZENDE, S. B.; CORRÊA, G. F. Pedologia: base e para distinção de ambientes. 5 ed. Lavras: Editora UFLA, 2007. 131p.

RIBEIRO, J. C.; SALOMÃO, F. X. T. Abordagem morfopedológica aplicada ao diagnóstico e prevenção de processos erosivos na bacia hidrográfica do alto rio da casca, MT. Revista Geociências, São Paulo, v. 22, n. 1, p. 83-95, 2003.

ROSA, R.; SANO, E. E.; ROSENDO, J. S. Estoque de carbono em solos sob pastagens cultivadas na bacia hidrográfica do Rio Paranaíba. Sociedade \& Natureza, Uberlândia/MG, v. 26, n. 2, p. 333-351, 2014.

ROSS, J. L. S. Ecogeografia do Brasil: subsídios para o planejamento ambiental. São Paulo: Oficina de Textos, 2006. 208p. 
ROUSE, J. W.; HAAS, R. H.; SCHELL, J. A.; DEERING, D. W. Monitoring vegetation systems in the great plains with ERTS. In: SYMPOSIUM OF SIGNIFICANT RESULTS OBTAINED WITH ERTS-1, 3., 1973, Maryland. Proceedings... Washington: NASA, 1973. p. 309-317.

SANTOS, H. G.; JACOMINE, P. K. T.; ANJOS, L. H. C.; OLIVEIRA, V. A.; LUMBRERAS, J. F.; COELHO, M. R.; ALMEIDA, J. A.; ARAÚJO FILHO, J. C.; OLIVEIRA, J. B.; CUNHA, T. J. F. Sistema Brasileiro de Classificação de Solos. 5. ed. Brasília: Embrapa, 2018. 356p.

TARIFA, J. R. Mato Grosso: clima - Análise e representação cartográfica. 1 ed. Cuiabá: Entrelinhas, 2011. 101p. UNEP. United Nations Environment Programme. Land degradation in drylands (LADA): GEF grant request. 2004. Disponível em: $<$ https://www.thegef.org/project/land-degradation-assessment-drylands-lada $>$.

USGS. United States Geological Survey. EarthExplorer. 2016. Disponível em: <https://earthexplorer.usgs.gov/>.

XAVIER, F. V.; CUNHA, K. L.; SILVEIRA, A.; SALOMÃO, F. X. T. Análise da suscetibilidade à erosão laminar na bacia do rio Manso, Chapada dos Guimarães, MT, utilizando Sistemas de Informações Geográficas. Revista Brasileira de Geomorfologia, Curitiba, v. 11, n. 2, p. 51-60, 2010

\section{COMO CITAR ESTE TRABALHO}

Ramos, A.W.P; Galvanin. E.A. dos Santos; Xavier, V.F; Batista, V.F; Soares, B.R.B \& Azevedo, U.R.Estudo da conservação ambiental das pastagens da municipalidade de Araputanga - MT, Brasil. Revista Tamoios, São Gonçalo, v. 17, n. 2, p. 137-157, 2021. Disponível em: https://doi.org/10.12957/tamoios.2021.59793. Acesso em: DD MM. AAAA. 